\title{
Novel occurrence of Acute Ischaemic Stroke and DVT simultaneously in a patient of Scrub Typhus: A case report
}

\author{
Sampurna Chowdhury ${ }^{1}$, Rishav Mukherjee ${ }^{2}$, Pradip Kumar Sinha ${ }^{3}$ \\ ${ }^{1,2}$ Post Graduate Trainee, ${ }^{3}$ Professor and Head, Department of General Medicine, Medical College, Kolkata
}

Orientiatsutsugumashi (erstwhile Rickettsia tsutsugumashi) is an obligate intracellular bacteria that is showing re-emergence in the last decade in eastern India. ${ }^{1-3}$ Commonly it causes acute febrile illness with rash and multiple organ involvement including CNS - In fact, Scrub encephalopathy has become a common cause of AES in recent times. Although pathogenesis of Scrub typhus is still uncertain, research on other Rickettsiales suggest infection of endothelial cells and vascular dysfunction to be the main mechanism. Based on that pathology we report two very rare manifestations - Acute Ischaemic Stroke and DVT in a single patient of Scrub typhus, occurring simultaneously. No such simultaneous occurrence has been reported in literature till date.

Keywords: Scrub Typhus; Stroke; DVT; Doxycycline

\section{Access this article online}

Website:

http://nepjol.info/index.php/AJMS DOI: $10.3126 /$ ajms.v11i4.28895

E-ISSN: 2091-0576 P-ISSN: 2467-9100

Copyright (c) 2020 Asian Journal of Medical Sciences

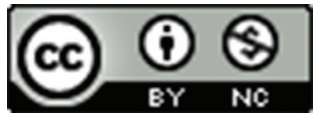

This work is licensed under a Creative Commons Attribution-NonCommercial 4.0 International License.

\section{CASE REPORT}

A 52-year-old non - diabetic, non-hypertensive man presented to our OPD with fever with confusion for 10 days followed by a sudden onset slurring of speech since the day before. He denied having any weakness of limbs, any seizures or any diminution of vision. He was a farmer by profession and lived in a mud hut, in the outskirts of the city, adjacent to a nearby field. His family history was unremarkable. He denied having $\mathrm{h} / \mathrm{o}$ TB or of TB contact. On examination patient was found to be febrile, conscious but drowsy. $\mathrm{BP}=122 / 84 \mathrm{mmHg}, \mathrm{P}=88 / \mathrm{min}$, regular, $\mathrm{CBG}=128 \mathrm{mg} / \mathrm{dl}$, $\mathrm{RR}=30 / \mathrm{min}$ Pupils - Normal in size and normally reactive to light. Neck rigidity absent, Kernig's sign absent. Plantar was extensor on the right but flexor on left. NIHSS - 10. His Hb= $10.8 \mathrm{gm} \%$, TC $=8750 \mathrm{cu} \mathrm{mm} \mathrm{N61L34} \mathrm{Platelets}=1.79$ lakh $\mathrm{Ur} / \mathrm{Cr}=18 / 0.9 \mathrm{Na}+/ \mathrm{K}+=134 / 4.2$, Procalcitonin $=0.020$.
Chest X-Ray was normal, ECG depicted Sinus tachycardia, regular rhythm. 2D Echo - WNL, No clots/ No RWMA. Carotid Artery Doppler - No plaques or narrowing noted.

Lipid Profile $(\mathrm{mg} / \mathrm{dl}): \mathrm{TG}=80$, Cholesterol $=84, \mathrm{HDL}$

$$
=40 \text {. }
$$

CSF study was performed which revealed Protein $=64.3 \mathrm{mg} / \mathrm{dl}$, Glucose $=72 \mathrm{mg} / \mathrm{dl} ;$ Total Count $=10$ (occasional lymphocytes) $\mathrm{ADA}=1.2, \mathrm{CBNAAT}$ of $\mathrm{CSF}=$ not detected. JE IgM ,both serum and CSF -Non reactive.

Dengue IgM of serum - not detected. Serum IgM of Scrub Typhus however was positive.

NCCT Brain was done to rule out hemorrhagic CVA. Acute infarcts (Figures 1 and 2) in B/L Occipito- parietal region 

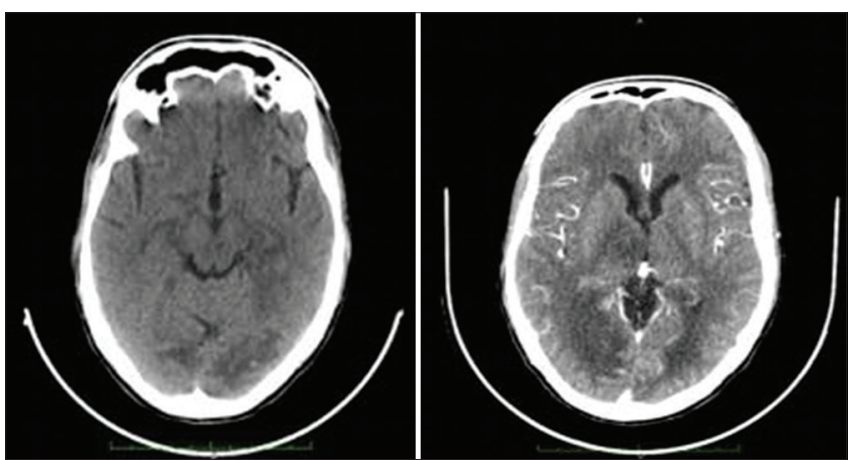

Figure 1: NCCT Brain showing acute infarcts in bilateral occipitoparietal region, thalamus (Rt>Lt)
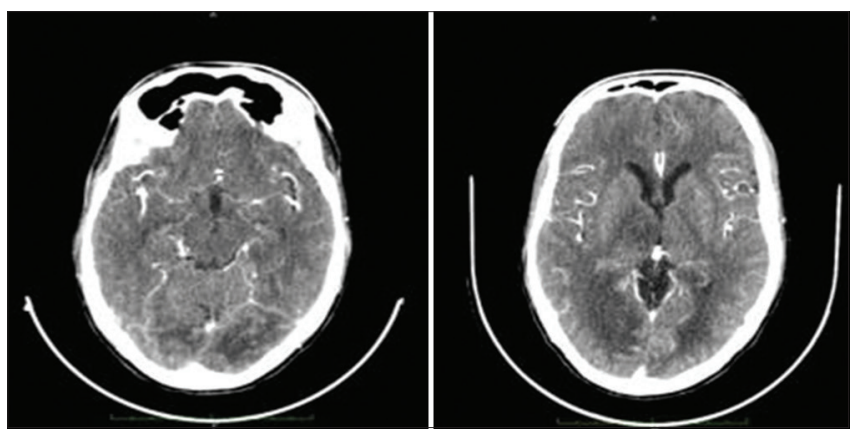

Figure 2: CECT Brain of the same patient. Basal exudates or Venous sinus thromboses were not noted

and medial Thalamic areas (Rt $>\mathrm{LT}$ ) along with acute Infarct in B/L Cerebellum were seen on NCCT Brain. MRI brain showed Diffusion Restriction in those areas and mainly involved the PCA territory (Figure 3).

CT Angiography was performed but it failed to show any obvious abnormalities. Larger vessels including those in the affected territories appeared unremarkable and there was no evidence of occlusion/ aneurysmal dilatation of the same (Figure 4). On the basis of a normal angiography with PCA infarct and on the background of Scrub Typhus,smaller vessels were assumed to be affected with a strong suspicion of CNS Vasculitis.

Patient was started on Anti platelets, Statin and IV Doxycycline. His fever subsided within a day - however on the third day of his hospital stay he developed DVT in his Right Popliteal Vein. He was initiated on LMWH and managed conservatively, resolving within Day 10 of admission, as observed on serial bilateral lower limb color doppler.

\section{DISCUSSION}

Pathogenesis of Rickettsial organisms which include Orientia, Ehrlichia and Anaplasma, are poorly understood. However, it appears to act by adhesion and invasion

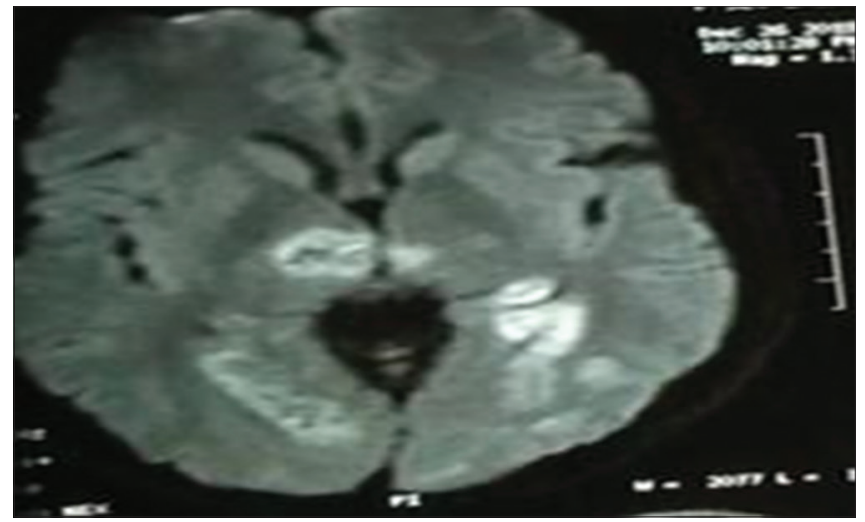

Figure 3: MRI brain showing diffusion restriction

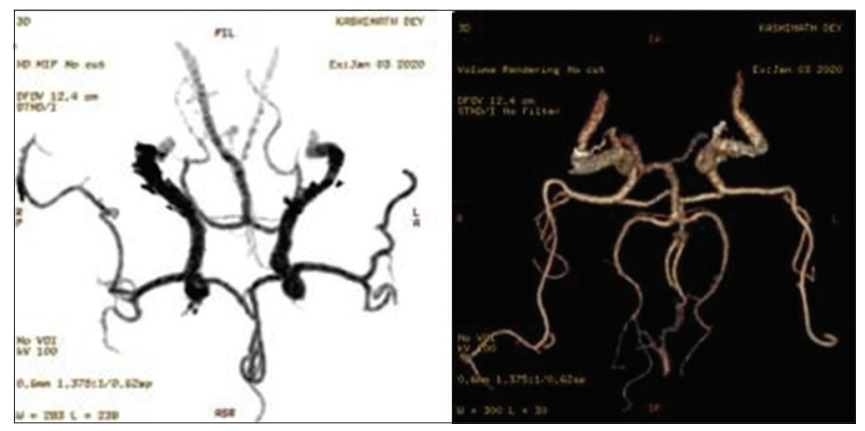

Figure 4: CT Angiography did not show any large vessel occlusion or aneurysms

of the endothelium lining the various vascular beds. There is release of von Willebrand factor along with thrombomodulin and tissue factor expression from the infected cells. ${ }^{4}$ They avoid detection by phagocytes ${ }^{5}$ and spread in contiguous fashion through a network of infected cells. This can manifest as maculo -papular rash when affecting cutaneous vessels. Thus systemic vasculitis and peri-vasculitis seem to be the main pathology ${ }^{1,6}$ Vascular injury to lungs, heart and brain results in Interstitial pneumonia, Myocarditis and Perivascular glial nodules in CNS respectively - other areas of distribution include skin, GIT, Pancreas, Liver, muscles and kidneys. Brain biopsy at autopsy may show severe lesions in Thalami and Brainstem. ${ }^{7}$ The angitis is most marked in the skin, heart, nervous system, skeletal muscle and kidneys. If local thrombosis is extensive, it can cause gangrene of skin and distal part of extremities. CNS Rickettsial infection includes a spectrum including Encephalitis, Meningoencephalitis, Meningitis commonly. ${ }^{8} \mathrm{~A}$ few authors have also reported on long term sequelae of CNS manifestations including Abducens nerve palsy, B/L Facial Nerve Palsy, hemiplegia, visual and hearing disturbances. ${ }^{9} 10$ They have known to persist for a few weeks. ${ }^{11-14}$

In mice, Rickettsiae have been found to reappear in CSF later. A few case reports on Acute Ischaemic Stroke ${ }^{15}$ and a single report of $\mathrm{DV}^{16}{ }^{16}$ were found after extensive literature 
search. In this exceptional case, both arterial and venous thrombosis seem to have occurred together. Scrub typhus, off late has been a public health problem in India during monsoon, with variable clinical presentations to which the practicing clinician should be abreast of. It responds well to Doxycycline thus preventing further clinical deterioration, if detected early. Public health measures aimed at mitigating this re emergent infection will assist in disease prevention and control.

\section{REFERENCES}

1. Rathi $\mathrm{N}$ and Rathi A. Rickettsial infections: Indian perspective. Indian Pediatr 2010; 47: 157-164.

https://doi.org/10.1007/s13312-010-0024-3

2. Rahi M, Gupte MD, Bhargava A, Varghese GM and Arora R. DHRICMR guidelines for diagnosis and management of rickettsial diseases in India. Indian J Med Res 2015; 141: 417-422. https://doi.org/10.4103/0971-5916.159279

3. Khan SA, Bora T, Laskar B, Khan AM and Dutta P. Scrub typhus leading to acute encephalitis syndrome, Assam, India. Emerg Infect Dis 2017; 23: 148-150.

https://doi.org/10.3201/eid2301.161038

4. N Teysseire, Arnoux D, George F, Sampol J and Raoult D. Von Willebrand Factor Release and Thrombomodulin and Tissue Factor Expression in Rickettsia Conorii-Infected Endothelial Cells. Infect Immun 1992; 60(10):4388-4393.

https://doi.org/10.1128/IAl.60.10.4388-4393.1992

5. Chan-Ki Min and Nam-Hyuk Cho. Subversion of Innate Phagocytic Cells by Orientia tsutsugamushi Autophagy: Cancer, Other Pathologies, Inflammation, Immunity, Infection, and Aging, 2016

6. Scrub typhus and other tropical rickettsioses; Nicholas P J Day, Didier Raoult in Infectious Diseases (Third Edition), 2010

7. Wenzel RP, Hayden FG, Gröschel DH, Salata RA, Young WS,
Greenlee JE, et al. Acute Febrile Cerebro-vasculitis: A Syndrome of Unknown, Perhaps Rickettsial, Cause. Ann Intern Med 1986; 104(5):606-615.

https://doi.org/10.7326/0003-4819-104-5-606

8. Sekeyová Z, Danchenko M, Filipčík $P$ and Fournier PE. Rickettsial infections of the central nervous system. PLOS Neglected Tropical Diseases 2019; 13(8): e0007469. https://doi.org/10.1371/journal.pntd.0007469

9. Mittal M, Thangaraj JWV, Rose W, Verghese VP, Kumar CPG, Mittal M, et al. Scrub Typhus as a Cause of Acute Encephalitis Syndrome, Gorakhpur, Uttar Pradesh, India. Emerg Infect Dis 2017; 23(8):1414-1416. https://doi.org/10.3201/eid2308.170025

10. Dinesh KN, Arun BT, Vijayadevagaran V, Ananthakrishnan S and Kittu D. Clinical Profile of Scrub Typhus Meningoencephalitis among South Indian Children. J Trop Pediatr 2018; 64:472-478. https://doi.org/10.1093/tropej/fmx096

11. Steinfeld HJ, Silverstein J, Weisburger $W$ and Rattner F. Deafness associated with Rocky Mountain spotted fever. Md Med J 1988; 37:287-288.

12. Massey EW, Thames T, Coffey CE and Gallis HA. Neurologic complications of Rocky Mountain spotted fever. South Med J 1985; 78:1288-1290. https://doi.org/10.1097/00007611-198511000-00004

13. Archibald LK and Sexton DJ. Long-term sequelae of Rocky Mountain spotted fever. Clin Infect Dis 1995; 20:1122-1125. https://doi.org/10.1093/clinids/20.5.1122

14. Sexton DJ and Kirkland KB. Rickettsial infections and the central nervous system. Clin Infect Dis 1998; 26:247-248. https://doi.org/10.1086/517043

15. Boulahri T, Taous A, Berri MA, Traini I, Elbenaye J and Rouimi A. Association rickettsiose et infarctuscérébral: une nouvelle observation The Pan African Medical Journal 2017; 26:80. https://doi.org/10.11604/pamj.2017.26.80.11434

16. Honnutagi RM, Reddy KS, Biradar MS and Patil SS. Deep vein thrombosis - a complication of rickettsial fever. International Journal of Research and Review 2019; 6(8):177-180.

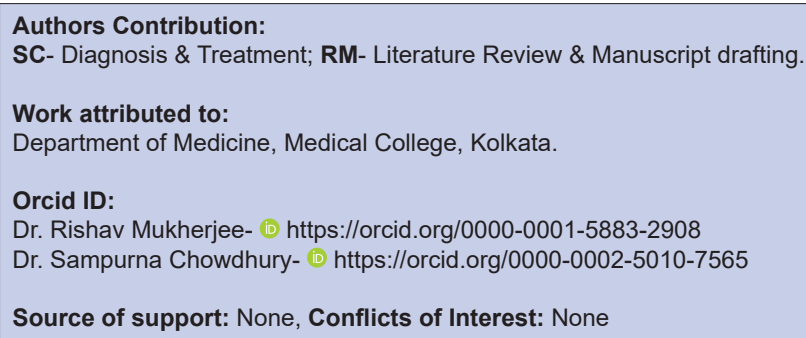

